\title{
Discrimination study between carcass yield and meat quality by gender in Korean native cattle (Hanwoo)
}

\author{
Do-Gyun Kim ${ }^{1, a}$, Joon-Yong Shim ${ }^{1,2, a}$, Byoung-Kwan Cho ${ }^{1}$, Collins Wakholi', \\ Youngwook $\mathrm{Seo}^{3}$, Soohyun $\mathrm{Cho}^{4}$, and Wang-Hee Lee ${ }^{1, *}$
}

\section{* Corresponding Author: Wang-Hee Lee Tel: +82-42-821-6720, Fax: +82-42-823-6246, E-mail: wanghee@cnu.ac.kr \\ ${ }^{1}$ Department of Biosystems Machinery Engineering, Collage of Agricultural and Life Science, Chungnam National University, Daejeon 34134, Korea \\ ${ }^{2}$ Agricultural Bigdata Division, Rural Development Administration, Jeonju 54875, Korea \\ ${ }^{3}$ National Institute of Agricultural Sciences, Rural Development Administration, Jeonju 54875, Korea ${ }^{4}$ Animal Products Utilization Division, National Institute of Animal Science, Rural Development Administration, Wanju 55365, Korea \\ a These authors contributed equally to this work.}

ORCID

Do-Gyun Kim

https://orcid.org/0000-0002-0962-6515

Joon-Yong Shim

https://orcid.org/0000-0003-0710-784X

Byoung-Kwan Cho

https://orcid.org/0000-0002-8397-9853

Collins Wakholi

https://orcid.org/0000-0003-0635-9463

Youngwook Seo

https://orcid.org/0000-0003-2140-5333

Soohyun Cho

https://orcid.org/0000-0002-8073-8771

Wang-Hee Lee

https://orcid.org/0000-0002-8834-1779

Submitted Jun 6, 2019; Revised Jul 17, 2019; Accepted Aug 19, 2019
Objective: The aim of this study was to identify a distribution pattern of meat quality grade (MQG) as a function of carcass yield index (CYI) and the gender of Hanwoo (bull, cow, and steer) to determine the optimum point between both yield and quality. We also attempted to identify how pre- and post-deboning variables affect the gender-specific beef quality of Hanwoo.

Methods: A total of 31 deboning variables, consisting of 7 pre-deboning and 24 post-deboning variables from bulls $(n=139)$, cows $(n=69)$, and steers $(n=153)$, were obtained from the National Institute of Animal Science (NIAS) in South Korea. The database was reconstructed to be suitable for a statistical significance test between the CYI and the MQG as well as classification of meat quality. Discriminant function analysis was used for classifying MQG using the deboning parameters of Hanwoo by gender.

Results: The means of CYI according to $1+, 1,2$, and 3 of MQG were $68.64 \pm 2.02,68.85 \pm$ $1.94,68.62 \pm 5.88$, and $70.99 \pm 3.32$, respectively. High carcass yield correlated with low-quality grade, while high-quality meat most frequently was obtained from steers. The classification ability of pre-deboning parameters was higher than that of post-deboning parameters. Moisture and the shear force were the common significant parameters in all discriminant functions having a classification accuracy of $80.6 \%, 71 \%$, and $56.9 \%$ for the bull, cow, and steer, respectively.

Conclusion: This study provides basic information for predicting the meat quality by gender using pre-deboning variables consistent with the actual grading index.

Keywords: Hanwoo; Carcass Grade; Carcass Yield; Meat Quality; Discriminant Function Analysis

\section{INTRODUCTION}

Carcass grade is not only a standard for production, distribution, and consumption but also for the quality index for consumer selection [1]. The main determinants of carcass grade are carcass yield and meat quality, which considerably influence price $[2,3]$. Under the recent domestic system, the grade of carcass yield is categorized as $\mathrm{A}, \mathrm{B}$, or $\mathrm{C}$, and the yield is determined as a function of carcass weight, backfat thickness, and ribeye area. Five grades of $1++, 1+, 1,2$, or 3 are assigned for meat quality by judges' following specific grading criteria based on marbling score, meat color, fat color, meat texture, and skeletal maturity at inspection [4].

Carcass yield is known to influence profits of distribution companies, whereas meat quality is directly related to consumer's purchasing. In general, both carcass yield and meat quality should be simultaneously superior for a high price. However, carcass yield and meat quality grades (MQGs) are inversely proportional, suggesting that a balance between them 
is necessary. For this reason, various studies have investigated factors that determine either carcass yield or meat quality. With regard to meat quality, these studies have revealed that various factors, such as marbling score and water-holding capacity (WHC) [5], Warner-Bratzler shear force [6], cooking loss [7], $\mathrm{pH}[8]$, and refrigerating methods and aging [9], affect meat quality. For example, it has been reported that the better the carcass yield grade (CYG), the lower the MQG [10]. Even though an increase in backfat thickness has a positive effect on meat grade, there is a limitation on improving the quality grade [11]. While the backfat thickness of bulls, cows, and steers has a positive correlation with skeletal maturity and fat color in meat quality indexes, it has a negative correlation with meat color [12]. Moreover, it is reported that marbling score and backfat thickness are positively correlated, but an increase of backfat thickness by improving marbling score can cause a reduction in the carcass yield index (CYI) [13]. In addition, meat color, which is one of the determinant factors for meat quality, is a dominant consumer preference because they generally prefer scarlet-colored beef [14]. Additionally, there are studies evaluating the genetic relationship between carcass traits and carcass price [2], the effect of backfat thickness on the factor of carcass grade and price [12], contribution of yield and quality traits of Hanwoo to auction price [15], and contribution of the carcass trait to the price of Hanwoo steer [16].

Most of the previous studies have focused on the effect of meat quality and carcass yield on pricing factor in gender, and the research on the relationship between the grades of carcass yield and the meat quality according to gender is limited. Therefore, the aim of this study was to identify a distribution pattern of MQG as a function of CYI and the gender of Hanwoo (bull, cow, and steer) so that we can provide fundamental data for determining the optimum point that satisfies both yield and quality. We also attempted to identify significant deboning positions for judging meat quality through the application of discriminant analysis on pre- and post-deboning variables.

\section{MATERIALS AND METHODS}

\section{Data description}

The raw data from 2005 to 2008 were obtained from the National Institute of Animal Science (NIAS) in South Korea. The raw data included various pre- and post-deboning variables and recorded grades of yields, marbling, meat color, fat color, and meat quality. Because this study focused on identifying pre- and post-deboning variables discriminating carcass yield and meat quality by gender, the database was reconstructed to be suitable for a statistical significance test between the CYI and the MQG as well as a classification of meat quality [17]. The total deboning variables was 31 and included 7 pre-debon- ing and 24 post-deboning variables from bulls $(n=139)$, cows $(\mathrm{n}=69)$, and steers $(\mathrm{n}=153)$. In detail, the 7 pre-deboning variables included cold carcass weight, ribeye area, back-fat thickness, moisture, cooking loss, shear force, and WHC. The 24 post-deboning variables included weight of retail cuts, body fat, bone, visceral fat, tenderloin, hanging tender, strip loin, loin, chuck, top round, bottom round, blade, fore-shank, hindshank, brisket, flank, rib, fore-leg bone, hind-leg bone, tail, knee bone, doggy bone, flank fat, and tail fat. Detailed information regarding variables and cattle is described previously [17].

\section{Grade of carcass yield and meat quality}

The CYG is classified on a scale of A, B, or C depending on the CYI calculated by carcass weight, back-fat thickness, and ribeye area. MQG is classified on a scale of $1++, 1+, 1,2$, and 3 depending on marbling score, meat color, fat color, texture, and maturity. In this study, however, we grouped together with the $1++$ and $1+$ grades because the $1++$ grade was too small to analyze. Basic statistics of CYI was calculated as a function of CYG.

\section{Statistical analysis}

Discriminant function analysis (DFA) is a multivariate statistical method used for classifying multiple populations. The core of DFA is discriminant functions (DFs) determining classification points into corresponding groups [18]. DFs are created from a linear combination of the independent variables to find a new axis that maximizes the variance among groups of dependent variables (equation 1).

$$
z=a+w_{1} x_{1}+w_{2} x_{2}+w_{3} x_{3}+\ldots+w_{\mathrm{n}} x_{\mathrm{n}}
$$

Where $z$ is the discriminant score; $a$ is the intercept; $w_{\mathrm{n}}$ is the discriminant weights of the $n$th dependent variable; $x_{\mathrm{n}}$ is the $n$th independent variable.

Due to its classification ability, DFA has been widely applied in various fields. In particular, DFA has been applied for studies on Hanwoo, such as classifying Hanwoo genders by pre- and post-deboning variables [17], taste grading of Hanwoo beef [19], classifying geographic origins of beef [20], and analyzing images to classify tough and tender beef in bulls [21]. For this reason, this study adopted DFA to discriminate MQG using deboning parameters of Hanwoo by gender.

\section{Statistical software}

All statistical analyses were performed using the SAS software package (ver. 9.4, SAS Institute Inc., Cary, NC, USA). Statistical significance was assumed when the p-value was less than 0.05 . 


\section{RESULTS AND DISCUSSION}

Distribution of quality grade by carcass yield index

Analysis of variance and post-hoc test were performed using CYI to analyze its distribution by MQG. The means of CYI according to $1+, 1,2$, and 3 of MQG were $68.64 \pm 2.02$, $68.85 \pm$ $1.94,68.62 \pm 5.88$, and $70.99 \pm 3.32$, respectively (Table 1). Grade 3 was significantly different from grade $1+, 1$, and 2 , whereas grade $1+, 1$, and 2 were not significantly different from each other (Figure 1). MQG of $1+, 1$, and 2 were correlated to CYG of B, while the MQG of 3 correlated to CYG of A. Therefore, it appeared that the lowest grade of meat quality matched the highest grade in CYI, and better quality meat was obtained at lower yields. This is consistent with a previous study that showed that a high amount of carcass limits the high level of MQG [10]. The numbers of bulls, cows, and steers in the best grade (1+ grade) of Hanwoo were $0(0 \%), 2(6 \%)$, and $32(94 \%)$, respectively (Figure 2). In general, most of the bulls showed low-quality grade with high carcass yield, while over half of the steers were in the upper level of MQG and less than 10\% of steers belonged to the $3 \mathrm{MQG}$. The majority of cows were distributed over an MQG of either 1 or 2 . The above distributions are consistent with a previous study showing that a high level of meat quality is observed in the order of steer, cow, and bull [22].

Prediction of quality grade by using pre- and postdeboning data

DFA was applied to investigate the possibility of using pre-
Table 1. Basic statistics of each carcass yield index in Hanwoo

\begin{tabular}{lccc}
\hline Carcass yield index & N & Mean & Standard deviation \\
\hline $1+$ & 34 & 68.84 & 2.02 \\
1 & 66 & 68.85 & 1.94 \\
2 & 124 & 68.62 & 5.88 \\
3 & 137 & 70.99 & 3.32 \\
Total & 361 & 69.58 & 4.27 \\
\hline
\end{tabular}

and post-deboning data in classifying meat quality by gender. The discrimination accuracy with 7 pre-deboning variables for a total number of data regardless of gender was $64.6 \%$, and those for $1+, 1,2$, and $3 \mathrm{MQG}$ were $58.9 \%, 59.1 \%, 57.3 \%$, and $83.2 \%$, respectively (Table 2 ). The significant variables in discrimination were moisture, WHC, shear force, and backfat thickness in order. This result is consistent with the fact that the marbling score differs by the moisture contents [5,23], and the shear force is a determinant factor affecting MQG [24]. When 24 post-deboning variables were applied, the total discrimination accuracy was $59.7 \%$ and accuracy was $70.6 \%$, $53.0 \%, 43.6 \%$, and $71.5 \%$ for $1+, 1,2$, and 3 MQG, respectively (Table 3 ). The weights of retail cuts, bone, top round, chuck, body fat, hind-leg bone, striploin, brisket, hind-shank, rib, loin, blade, fore-leg bone, doggy bone, bottom round, fore-shank, hanging tender, and tail were significant variables affecting meat grade classification in order [25]. Overall, despite the larger number in post-deboning variables than in pre-deboning, the DF based on pre-deboning variables showed high classification ability, and this might be possible because

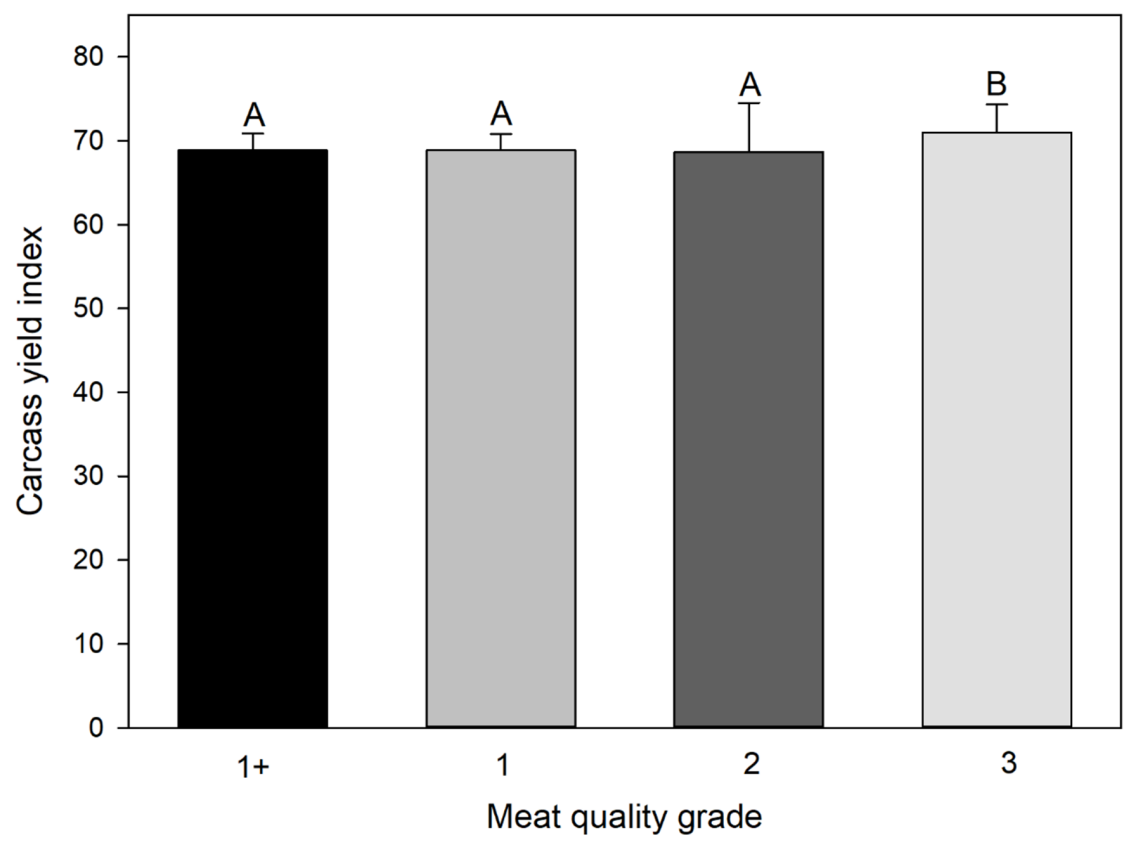

Figure 1. Comparison of the means of the carcass yield index grouping by the meat quality grade. Different alphabets on the bar indicate that the group mean is different, suggesting the grade 3 is significantly different from grade 1+, 1, and 2, while grade 1+, 1, and 2 are not different with each other. 


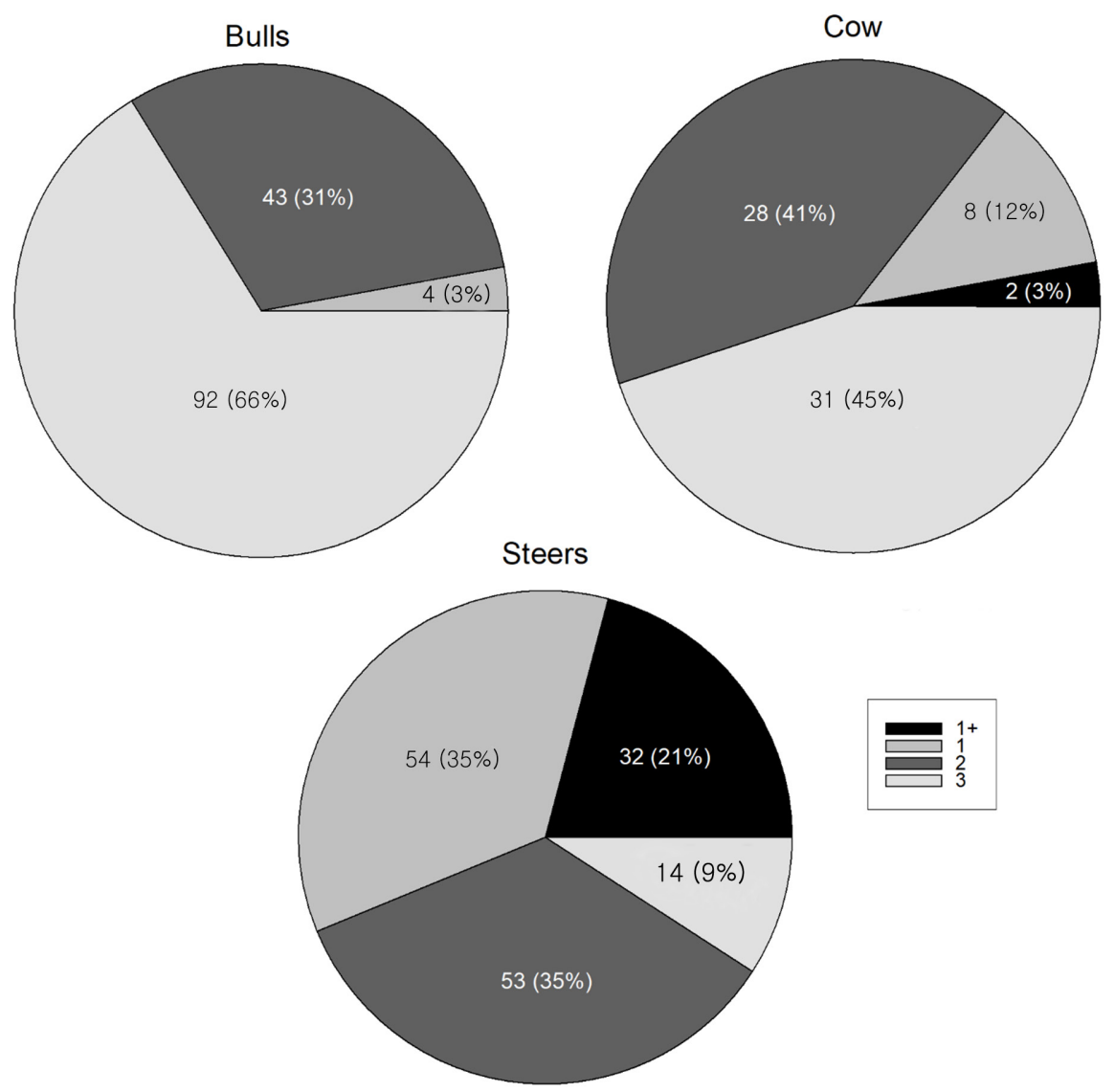

Figure 2. Pie chart showing the distribution of the meat quality grade according to the gender. Numbers in the pie chart indicate the number of $1+, 1,2$, and 3 grades in bulls, cows, and steers with their portions in percentage.

grading carcass yield and meat quality were carried out before the deboning [26].

We further performed DFA for each gender of Hanwoo
(Tables 2, 3). As a result of classification using pre- and postdeboning variables from 139 numbers of bulls, the total accuracy and its coefficient determination of DF were $80.6 \%$ and $96.5 \%$,

Table 2. Discriminant analysis of meat quality using pre-deboning variables

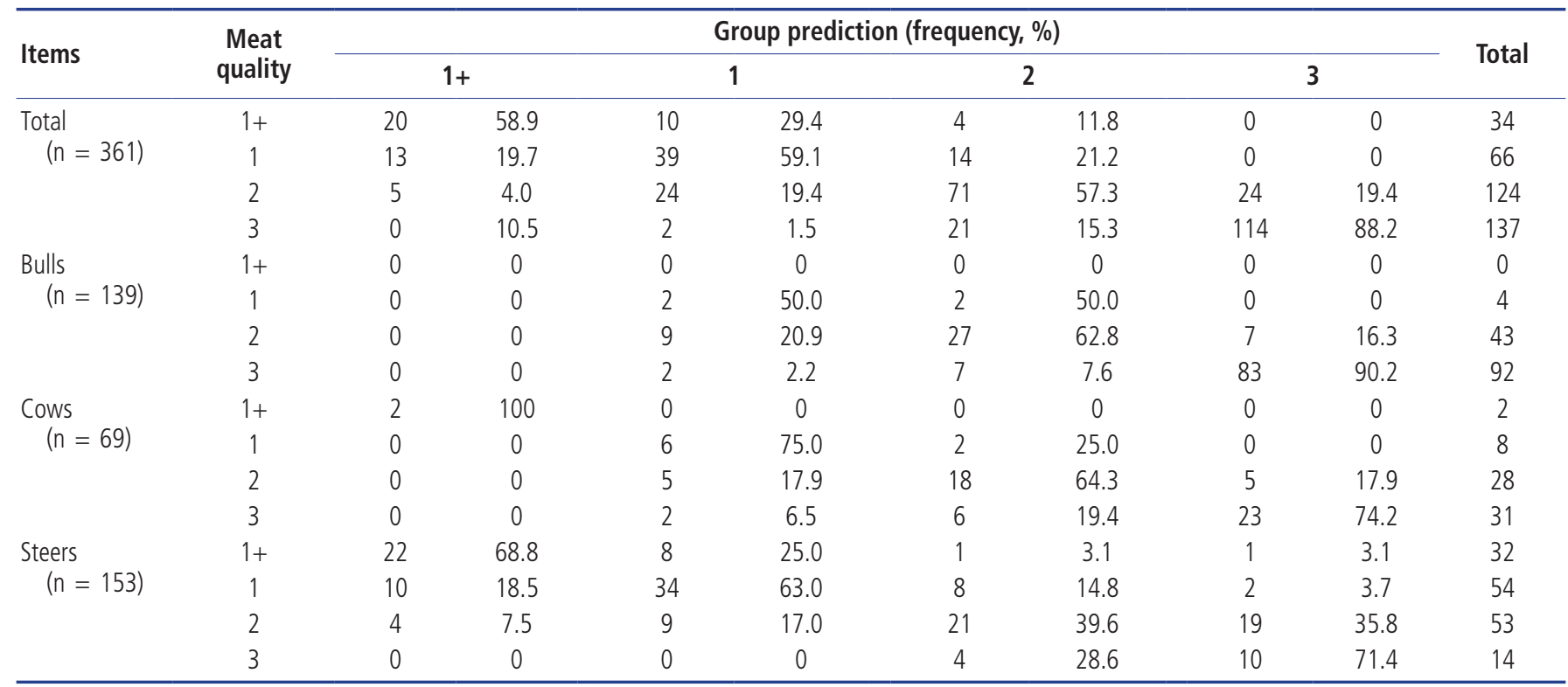


Table 3. Discriminant analysis of meat quality using post-deboning variables

\begin{tabular}{|c|c|c|c|c|c|c|c|c|c|c|}
\hline \multirow{3}{*}{$\begin{array}{l}\text { Items } \\
\text { Total }\end{array}$} & \multirow{3}{*}{$\begin{array}{c}\begin{array}{c}\text { Meat } \\
\text { quality }\end{array} \\
1+\end{array}$} & \multicolumn{8}{|c|}{ Group prediction (frequency, \%) } & \multirow{3}{*}{\begin{tabular}{r|} 
Total \\
34
\end{tabular}} \\
\hline & & \multicolumn{2}{|c|}{$1+$} & \multicolumn{2}{|c|}{1} & \multicolumn{2}{|c|}{2} & \multicolumn{2}{|c|}{3} & \\
\hline & & 25 & 70.6 & 5 & 14.7 & 5 & 14.7 & 0 & 0 & \\
\hline \multirow{3}{*}{$(n=361)$} & 1 & 17 & 25.8 & 35 & 53.0 & 11 & 16.7 & 3 & 4.6 & 66 \\
\hline & 2 & 17 & 13.7 & 26 & 21.0 & 54 & 43.6 & 27 & 21.8 & 124 \\
\hline & 3 & 8 & 5.8 & 7 & 5.1 & 24 & 17.5 & 98 & 71.5 & 137 \\
\hline \multirow{4}{*}{$\begin{array}{l}\text { Bulls } \\
\qquad(n=139)\end{array}$} & $1+$ & 0 & 0 & 0 & 0 & 0 & 0 & 0 & 0 & 0 \\
\hline & 1 & 0 & 0 & 3 & 75.0 & 1 & 25.0 & 0 & 0 & 4 \\
\hline & 2 & 0 & 0 & 2 & 4.7 & 31 & 72.1 & 10 & 23.3 & 43 \\
\hline & 3 & 0 & 0 & 3 & 3.3 & 20 & 12.7 & 36 & 75.0 & 92 \\
\hline \multirow{4}{*}{$\begin{array}{l}\text { Cows } \\
\qquad(n=69)\end{array}$} & $1+$ & 2 & 100 & 0 & 0 & 0 & 0 & 0 & 0 & 2 \\
\hline & 1 & 0 & 0 & 7 & 87.5 & 1 & 12.5 & 0 & 0 & 8 \\
\hline & 2 & 0 & 0 & 4 & 14.3 & 20 & 71.4 & 4 & 14.3 & 28 \\
\hline & 3 & 0 & 0 & 2 & 6.5 & 7 & 22.6 & 22 & 71.0 & 31 \\
\hline \multirow{4}{*}{$\begin{array}{l}\text { Steers } \\
\qquad(n=153)\end{array}$} & $1+$ & 19 & 59.4 & 6 & 18.8 & 3 & 9.4 & 4 & 12.5 & 32 \\
\hline & 1 & 14 & 25.9 & 29 & 53.7 & 11 & 20.4 & 0 & 0 & 54 \\
\hline & 2 & 4 & 7.5 & 8 & 15.1 & 29 & 54.7 & 12 & 22.6 & 53 \\
\hline & 3 & 1 & 7.1 & 1 & 7.1 & 2 & 14.3 & 10 & 71.4 & 14 \\
\hline
\end{tabular}

and $74.1 \%$ and $69.6 \%$, respectively. Similar to using entire data, the classification ability as a function of pre-deboning data was higher than that with post-deboning data. The significant variables of pre-deboning were moisture, shear force, and cold carcass weight and classified bulls by meat quality of 1,2 , and 3 with an accuracy of 50\%, 62.8\%, and $90.2 \%$, respectively. The high accuracy observed in bulls seemed that bulls had more moisture content $[17,23]$, which significantly affected meat quality compared to others $[6,12,23]$. The significant variables of post-deboning data were body fat, rip, striploin, tail, hanging tender, top round, hind-shank, bone, hind-leg bone, and doggy bone. Body fat and rip only showed high correlation with DF, while the other variables showed weak correlations. The accuracies for MQG 1, 2, and 3 were $75 \%$, $72.1 \%$, and $75 \%$, respectively. In the case of cows, the significant discriminant variables using pre-deboning were moisture, backfat thickness, and ribeye area, which were consistent with the indices used by domestic judges in practical grading field [26]. This consistency might lead to high accuracy in cows, resulting in $100 \%, 75 \%, 64.3 \%$, and $74.2 \%$ for MQG of $1+, 1,2$, and 3 , respectively. In contrast, post-deboning variables were not significant in meat quality classification in cows. For steers, the pre-deboning data was able to classify MQG with 56.9\%, and significant variables were moisture content and shear force. Each discriminant accuracy was $68.8 \%, 63 \%, 29.6 \%$, and $71.4 \%$ for MQG $1+, 1,2$, and 3, respectively. When it uses post-deboning data, striploin, loin, body fat, blade, and weight of retail cuts were significant variables, but accuracy was low. As expected, pre-deboning variables showed high discrimination ability; thus, the results by them could be basic information for predicting the meat quality by gender. Also, the main discriminant vari- ables of post-deboning data were differed by gender. This might be due to the characteristic of meats, such as weight of deboning parts and the density, which were different by genders [18,27]. Thus, this analysis suggests that the application of the current post-deboning variables might not be suitable in classifying meat quality.

\section{Discussion on identification of optimal factors based on economics}

According to the Korean Statistical Information Service [28], the steer was the most frequently appeared gender in 1+ MQG (65\%) in 2018 and cow accounted for $23.4 \%$. However, bulls were merely emerged in $1+$ MQG $(0.5 \%)$. The average appearance frequency in $1 \mathrm{MQG}$ was in the order of cow $(34.3 \%)$, steer $(28.4 \%)$, and bull (3.6\%), whereas he average appearance frequency in MQG 2 was bull (94.8\%), cow (41.9\%), and steer $(11 \%)$ in order. Overall, there was a tendency for MQG to appear high in the order of steers, cows, and bulls, but MQG of bulls was remarkably low. In contrast, the average appearance frequency of A of CYG was in the order of bulls (78.1\%), cow $(20.4 \%)$, and steer (18.2\%). For B grade in CYG, cow was most common (50.2\%), while steer and bull accounted for $46.5 \%$ and $18.3 \%$, respectively. Grade C in CYG was in the order of steer $(35.2 \%)$, cow (28.9\%), and bull (2.4\%). Overall, these data showed that in CYG, the bull had the highest appearance frequency, whereas steer generally showed the lowest CYG. Because of the tendency of the inverse relationship between meat quality and carcass yield, Hanwoo farmers need to make a decision for a proper balance between them for maximizing profit. According to a study on the price change of carcasses by grading determinants of meat quality and yield, the effect of marbling and the carcass weight on total 
price was estimated by $46.3 \%$, and $52.4 \%$, respectively, and the marbling particularly was evaluated to contribute on auction price with $93.5 \%$ [15]. In addition, it was reported that the marbling was the significant factor affecting both carcass price and auction price in determining grid price and prediction of carcass composition [13], which indicates the importance of the meat quality factor in determining Hanwoo price. However, there was a domestic trend since 2011 that the price contribution in the meat quality has declined, whereas that of carcass yield has increased. It seemed that a decrease in price contribution of meat quality was because of the decrease in Hanwoo price which caused to increase the number of slaughtered cattle and imported beef since 2011. In addition, increased frequency of MQG 1 or higher leads to decrease in discrimination ability of marbling score [28]. Moreover, a decrease in Hanwoo supply due to national policy led to an increase in price contribution of the carcass yield [16]. Therefore, it is necessary to decide whether to concentrate on the meat quality or the carcass yield, or to get optimal profit by considering them at the same time.

To specifically discuss price factors of Hanwoo, we reviewed previous reports regarding the determinants of Hanwoo price. According to a previous study, marbling score accounted for $61.2 \%$ of the variability of the auction price [2]. In the study, for carcass price, $43.9 \%$ of the variation was mainly affected by the cold carcass weight, whereas the eye muscle area had a negligible contribution to the auction price and the carcass price. Other previous study also showed that each contribution of carcass weight, eye muscle area, backfat thickness, and marbling score was $0.17 \%, 2.02 \%, 6.52 \%$, and $97.3 \%$ for the auction price, and $33.5 \%, 1.4 \%, 4.7 \%$, and $60.2 \%$ for the carcass price, respectively [29]. Lee et al [3] reported that the auction price had 0.73 of the highest correlation with the marbling score, and the carcass price had 0.71 and 0.61 of correlation with the carcass weight and the marbling score, respectively. Similarly, marbling accounted for $95.4 \%$ of the auction price $\left(\mathrm{R}^{2}=0.51\right)$, and $52.6 \%$ and $44.3 \%$ of the total price were attributable to marbling and carcass weight $\left(R^{2}=\right.$ $0.75)$, respectively [30]. Consequently, marbling and carcass weight were the most contributory factors among carcass traits and therefore, it will be possible to determine the optimal price through effective balance between these two factors. However, the livestock grading criteria has been recently revised [31]. The new grading system has developed CYI equations by genders and species and MQG grading criteria has been alleviated, which may cause increased $1++$ meat. In addition, the meat color, fat color, and meat texture feed are also incorporated into the grading criteria, and $1++$ meat should display its marbling score on a tag to reflect preference of consumers on grade [14]. Under the new system, it may be possible to achieve high grade in both MQG and CYI because the carcass weight reported to be inversely proportionated to MQG is managed to be a positive factor. Nevertheless, previous factors determining CYI and MQG are still used in the new system, suggesting pre/post-deboning variables can be a potential factor for discriminating grades. Moreover, this study is worthwhile to provide an example of applying multivariate analysis into livestock data.

Meat quality and carcass yield are important factors in determining the market price of Hanwoo, but they are known to be inversely proportional. For this reason, there is a demand for identifying a balance point which maximizes profits. In this point of view, this study investigated that the distribution of CYG according to MQG and analyzed variables in determining meat quality by gender. We showed that CYG was distributed in the low grade of meat quality, and the most dominant factor in meat quality was moisture, which affected the marbling score. Since the pricing factors tend to consider both carcass yield and meat quality at the same time and the tendency has systemically included in the revision of livestock grading criteria [31], it is expected to provide necessary information on judging based on distribution of carcass and its dominant factors for obtaining best profit.

\section{CONFLICT OF INTEREST}

We certify that there is no conflict of interest with any financial organization regarding the material discussed in the manuscript.

\section{ACKNOWLEDGMENTS}

This work was supported by a grant from the collaborative research project (No. PJ011815), Rural Development Administration, Republic of Korea.

\section{REFERENCES}

1. Indurain G, Carr TR, Goñi MV, Insausti K, Beriain MJ. The relationship of carcass measurements to carcass composition and intramuscular fat in Spanish beef. Meat Sci 2009;82:15561. https://doi.org/10.1016/j.meatsci.2009.01.005

2. Kim JB, Kim DJ, Lee JK, Lee CY. Genetic relationship between carcass traits and carcass price of Korean cattle. Asian-Australas J Anim Sci 2010;23:848-54. https://doi.org/10.5713/ajas.2010. 90555

3. Lee JJ, Choi SD, Dang CG, Kang SN, Kim NS. The effect of carcass traits on economic values in Hanwoo. Food Sci Anim Resour 2011;31:603-8. https://doi.org/10.5851/kosfa.2011.31. 4.603

4. Chung KY, Lee SH, Cho SH, Kwon EG, Lee JH. Current situation and future prospects for beef production in South Korea - A review. Asian-Australas J Anim Sci 2018;31:951-60. https://doi.org/10.5713/ajas.18.0187 
5. Lee JM, Choe JH, Lee HK, et al. Effect of quality grades on carcass characteristics, physico-chemical and sensory traits of longissimus Dorsi in Hanwoo. Food Sci Anim Resour 2010; 30:495-503. https://doi.org/10.5851/kosfa.2010.30.3.495

6. Lorenzen CL, Miller RK, Taylor JF, et al. Beef customer satisfaction: trained sensory panel ratings and Warner-Bratzler shear force values. J Anim Sci 2003;81:143-9. https://doi.org/ $10.2527 / 2003.811143 x$

7. George-Evins CD, Unruh JA, Waylan AT, Marsden JL. Influence of quality classification, aging period, blade tenderization, and endpoint cooking temperature on cooking characteristics and tenderness of beef gluteus medius steaks. J Anim Sci 2004; 82:1863-7. https://doi.org/10.2527/2004.8261863x

8. Muchenje V, Dzama K, Chimonyo M, Strydom PE, Hugo A, Raats JG. Some biochemical aspects pertaining to beef eating quality and consumer health: a review. Food Chem 2009;112: 279-89. https://doi.org/10.1016/j.foodchem.2008.05.103

9. Rhee MS, Wheeler TL, Shackelford SD, Koohmaraie M. Variation in palatability and biochemical traits within and among eleven beef muscles. J Anim Sci 2004;82:534-50. https://doi. org/10.2527/2004.822534x

10. Smith RL, Oltgen JW. Advanced genetics and value- based marketing. In: Cow-calf quality assurance hand book. Davis, CA, USA: University of California Cooperative Extension; 1996. p. 10-100.

11. Brethour JR. The relationship of average backfat thickness of feedlot steers to performance and relative efficiency of fat and protein retention. J Anim Sci 2004;82:3366-72. https:// doi.org/10.2527/2004.82113366x

12. Lee JM, Choe JH, Park HK, et al. Effect of backfat thickness on the carcass grade factors and carcass price in Hanwoo cows and steers. Food Sci Anim Resour 2011;31:280-9. https://doi. org/10.5851/kosfa.2011.31.2.280

13. Kim DJ, Lee CW, Lee CY, Kim JB. The influence of carcass traits on carcass price in mature Hanwoo cow. J Anim Sci Technol 2010;52:157-64. https://doi.org/10.5187/JAST.2010. 52.2.157

14. Kim BS, Lee YE. Effect of antioxidant on quality of ground beef during the refrigeration storage. Korean J Food Nutr 2011:24:422-33. https://doi.org/10.9799/ksfan.2011.24.3.422

15. Sun DW, Kim BW, Park JC, Lee JG. Effects of carcass traits on auction price in Hanwoo. J Anim Sci Technol 2012;54:7782. https://doi.org/10.5187/JAST.2012.54.2.77

16. Kim HK, Sun DW, Lim HT, Kong IK, Lee JG. Trend on contribution of carcass trait influencing price in Hanwoo steer. J Agric Life Sci 2017;51:119-25. https://doi.org/10.14397/jals. 2017.51.6.119

17. Shim JY, Kim HY, Cho BK, et al. Multivariate analysis of deboning data for classifying Hanwoo (Korean native cattle) by gender. Curr Sci 2018;114:1075-82. https://doi.org/10.18520/ cs/v114/i05/1075-1082

18. Afifi A, May S, Clark VA. Practical multivariate analysis. 5th ed. Boca Raton, FL, USA: CRC Press; 2011.

19. Cho SH, Seo G, Kim DH, Kim JH. Palatability grading analysis of Hanwoo beef using sensory properties and discriminant analysis. Food Sci Anim Resour 2009;29:132-9. https://doi. org/10.5851/kosfa.2009.29.1.132

20. Lim C, Son H, Hong E, Noh BS. Discrimination of geographical origin of beef using electronic nose based on mass spectrometer. Korean J food Sci Technol 2008;40:717-20.

21. Li J, Tan J, Shatadal P. Classification of tough and tender beef by image texture analysis. Meat Sci 2001;57:341-6. https:// doi.org/10.1016/S0309-1740(00)00105-4

22. Lee JM, Choe JH, Oh MH, et al. Effect of sex on quality grade factors, physicochemical and sensory traits of longissimus dorsi in Hanwoo. Food Sci Anim Resour 2010;30:321-7. https:// doi.org/10.5851/kosfa.2010.30.2.321

23. Lee JM, Choe JH, Jin HJ, et al. Effect of marbling score on carcass grade factors, physico-chemical and sensory traits of M. Longissimus Dorsi in Hanwoo. Food Sci Anim Resour 2012;32:659-68. https://doi.org/10.5851/kosfa.2012.32.5.659

24. Lee YJ, Kim CJ, Park BY, et al. Warner-Bratzler shear force, sarcomere length, total collagen contents and sensory characteristics of Hanwoo beef (Korean native cattle) quality grade. Food Sci Anim Resour 2009;29:726-35. https://doi.org/10. 5851/kosfa.2009.29.6.726

25. Dikeman ME, Cundiff LV, Gregory KE, Kemp KE, Koch RM. Relative contributions of subcutaneous and intermuscular fat to yields and predictability of retail product, fat trim, and bone in beef carcasses. J Anim Sci 1998;76:1604-12. https:// doi.org/10.2527/1998.7661604x

26. Cho SH, Kim J, Park BY, et al. Assessment of meat quality properties and development of a palatability prediction model for Korean Hanwoo steer beef. Meat Sci 2010;86:236-42. https:// doi.org/10.1016/j.meatsci.2010.05.011

27. Park GB, Moon SS, Ko YD, et al. Influence of slaughter weight and sex on yield and quality grades of Hanwoo (Korean native cattle) carcasses. J Anim Sci 2002;80:129-36. https://doi.org/ $10.2527 / 2002.801129 \mathrm{x}$

28. Korean Statistical Information Service [Internet]. Daejeon, Korea: Statistics Korea; 2018 [cited 2019 Feb 20]. Available from: http://kosis.kr/index/index.do

29. Kong JS, Choi TJ, Kim JI, et al. The analysis of the carcass traits contribution for Hanwoo Genetic evaluation. J Agric Life Sci 2016;50:83-9. https://doi.org/10.14397/jals.2016.50. 4.83

30. Park HR, Eum SH, Park JH, et al. Contribution analysis of carcass traits on auction price in Gyeongsangnam-do Hanwoo. J Agric Life Sci 2015;49:187-95. https://doi.org/10.14397/jals. 2015.49.6.187

31. Korea Ministry of Government Legislation: Grading of livestock products [Internet]. Sejong Korea: Ministry of Agriculture, Food and Rural Affairs; 2019 [cited 2019 Aug 2]. Available from: http://www.law.go.kr 